\title{
Determination of the protective effect of shark cartilage and shark liver oil (SLO) on colon cancer by using experimental DMH
}

\author{
MINE DOSAY-AKBULUT ${ }^{1}$, ELVAN AKGÜL ${ }^{2}$, FATIH BOZKURT $^{3}$ \\ ${ }^{1}$ Afyon Kocatepe University, Veterinary Faculty, Medical Biology and Genetics Dep., ANS Campus \\ Gazligol Road 03200, Afyon, Turkey \\ ${ }^{2}$ Afyon Kocatepe University, Dinar Scholl of Applied Sciences, Afyon, Turkey \\ ${ }^{3}$ Afyon Kocatepe University, Veterinary Faculty, Pathology Dep., Afyon, Turkey
}

\begin{abstract}
Objectives: It is a known fact that cancer is one of the biggest health problems. There are many different alternative products that are preferred for use among cancer patients. Our study is based on shark cartilage and liver oil as alternative products within alternative treatment (CAM) due to low incidence of cancer in sharks.

Method: With this study; it was aimed to search the toxic effects of DMH on colon, SC and SLO 's conservative effects against these toxic and carcinogic effects. 40 rats have been classified as follows: $40 \mathrm{DMH}$ group: 4; control group - 6; given DMH but not cured group - 15; given DMH and cured with SC group - 15; given DMH and cured with SLO group.

Results and Conclusion: The negative effects of DMH on biochemical, genetic, and pathological were observed in rat column; The treatment of SLO and SC against to colon cancer is thought to be associated with damage and regression of tumor cells. When we look at the numerical results, it can be said that SC is more successful and effective in correcting the effect of DMH. It can be said that our experimental model provides the desired aim and success in this direction.
\end{abstract}

Keywords DMH, Shark Cartilage(SC), Shark Liver Oil (SLO), Colon, Cancer.

To cite this article: AKBULUT MD, AKGÜL E, BOZKURT F. Determination of the protective effect of shark cartilage and shark liver oil (SLO) on colon cancer by using experimental DMH. Rom Biotechnol Lett. 2021; 26(3): 2618-2625. DOI: $10.25083 / \mathrm{rbl} / 26.3 / 2618-2625$ 


\section{Introduction}

It is a known fact that cancer disease is one of the biggest health problems. The five most common types of cancer in men and women in the world, are determined respectively; stomach, lung, breast, colon-rectum and cervical cancers. Incidence of cancer types shows differencess according to; age, gender, cancer developed organ and environmental factors.

Colorectal cancers are the third leading cancers in men and the second one in women, worldwide, cause of death among 694,000 people worldwide. (GLOBOCAN, 2012). Colon cancer rates are increasing due to changes in diet model. World-wide epidemiological investigations reveal the relationship between diet and gastrointestinal system tumors, particularly colorectal cancers. These studies have shown that a rich diet with meat increases cancer cases (SIDDİQUE et al, 2017). The incidence of colorectal carcinomas reaches the highest level of 60-70 years for human. Less than $20 \%$ of patients are under the age of 50 years. If we compare the cancer death rate in Turkey to other countries, we see that Turkey is among the 41 countries, 35 in men; 38th rank in women (AKGÜL and DOSAY AKBULUT, 2014).

1,2 Dimethylhydrazine (DMH), a potent carcinogen, is known to induce carcinogenesis of rat colon, mimicking the histopathology of human colonic epithelial neoplasms. DMH is widely used to stimulate colon cancer formation in rodents (AKTARUL et al, 2017).<smiles>CNNC</smiles>

\section{Dimethylhydrazine chemical structure}

DMH, a methyl hydrazine derivative, is an efficacious agent in the organism by converting methyl radical into releasing compounds. DMH, which has a mutagenic effect by methylating DNA molecules, also disrupts RNA and thus protein synthesis. The main pathway in the initiation of carcinogenesis with this substance; DMH is converted to azoxymethane and azoxymethanol in the liver. (Azoximeter is a carcinogenic and neurotoxic compound used in biological research. Azometan is an oxide and is particularly effective for induction of colon carcinoma) Azoxymethanol is then converted into active carcinogenic substances by bacterial hydrolysis in the colon lumen (KURAGUCHI, 2001).

The US National Health Center for Complementary and Alternative Medicine (NCCAM) was established for complementary and alternative medicine to conduct research, to make recommendations and guidance on CAM methods.

The data show that medicinal plants are widely used for the treatment of diseases with the name of complementary medicine all over the world and the interest in these plants increases day by day. Especially in recent years, interest in aromatherapy has increased and Chinese medicine has been rediscovered. Recently echinacea, ginseng, ginko, centaury and aloe vera etc. herbal drugs are available in large quantities in our medicine cabinets. The WHO reports that more than 20,000 plants have been used for medical treatment in more than 90 countries. Those who are interested in alternative treatment methods from cancer patients use many plants, primarily nettle, to support or relax medical treatment (BAYDAR, 2005).

There are many different alternative products that are preferred for use among cancer patients. Our study is based on shark cartilage and liver oil as alternative products due to the low incidence of cancer in sharks.

The amino acid exchange rate was 6 times slower in sharks on the basis of mitochondrial cytochrome $b$ gene sequence compare to mammals. In other words, more amino acid conservation results in the mutation or susceptibility of cells to cancer rare in sharks (PATRA and SANDELL, 2012).

The search for new anti-tumor compounds is getting more interest. The find out of antitumor activity in animals such as crocodiles, whales, sharks will encourage related research and has potential for the development of novel antitumor compound(s) (JEYAMOGAN, KHAN AND SIDDİUİ, 2017). For example; Marine animals' Glycosaminoglycans (GAGs) are different from land animals with its molecular weight and sulfation. Especially, chondroitin sulfate (CS) comes to forward. CS-E chains [GlcA-GalNAc(4S,6S)] have an antiviral and anti-metastatic activities (VALCARCEL et al, 2017).

Shark cartilage (SC) is a very potent inhibitor of tumor formation. The protein content of the shark cartilage is similar to that of bovine cartilage inhibiting tumor formation. Cartilage contains some specific molecules. These are chondromodulin-1, thrombospondin-1, type XVIII-derived endostatin, SPARC (acid and cysteinerich secreted protein), and type II collagen derivative N-terminal propeptide (PIIBNP) (PATRA and SANDELL, 2012). SC prevents the formation of new vessels in the tumor. Thus, the tumor that cannot be fed decreases and disappears in time. For this reason, it is seen as an ideal alternative medicine that can be used as a preventive against tumor formation due to the cartilage structure of the shark.

Alkylglycerols and squalene are the most important materials in the fight against infection and cancer. Shark liver oil (SLO) has a high level of alkylglycerols and squalene, and -3 EFA. Therefore, it is seen as an important alternative source for use against cancer and infections in one study, it was determined that 1-O-alkylglycerols derived from fish oils were effective in the combined treatment of antitumor content and different types of cancer (LEWKOWICZ and TCHORZEWSKİ, 2012).

It is also known that fish oil may increase apoptotic cells and lipid peroxidation of tumor cells and decrease the rate of proliferation. A study was performed to test the effect of these components on tumor growth. In this study, 
biochemical parameters of tumor weight, hydroperoxide content, proliferation rate and percentage of apoptotic tumor cells were obtained. After all; decreased tumor cells $(40 \%)$, increased tumor cell apoptosis ( 3 times), decreased tumor cell proliferation $(35 \%)$ were seen. As a result; It has been suggested that SLO extract can be used as a supplement to cancer treatment (IAGHER et al, 2013).

The aim of this study is to investigate the relationship between tumor growth and DMH in the colon and the protective effect of SC and SLO on pathological, genetic and biochemical levels.

\section{Materials and Method}

The applications was carried out with the permission obtained from Local Ethics Committee of Animal Experiments of Afyon Kocatepe University with etics rapor no: AKUHADYEK-239-13.

This study was supported by AKU-HADYEK Project No: 13.SAĞ.BİL.15

\section{Animal Materials}

The supplied 40 rats were grouped as follows.

40 DMH groups:

- 4 of them: Control group;

- 6 of them: DMH but not treated;

- 15 of them: Group treated with DMH and with shark cartilage;

- 15 of them: DMH given and treated with shark liver oil

- 4 rats in the DMH group were divided as control group and 36 rats were injected with DMH as subcutaneously everyday for 6.5 months. DMH doses were adjusted as $0.25 \mathrm{cc} \mathrm{DMH}+0.75 \mathrm{cc}$ for ethanol $=1 \mathrm{cc}$. DMH injection was applied to rats twice a week.

- Within DMH application; Group 1: control no treatment (6); Group 2: DMH+SC (for treatment) and Group 3: $\mathrm{DMH}+\mathrm{SLO}$ (for treatment). $0.2 \mathrm{gr} \mathrm{SC}$ was given to Group 2 and 0.5 gr SLO was given to Group 3 by gavage for each day for 1 month.

At the end of the study, all rats were sacrificed and tissue and blood samples were collected for biochemical, pathological and genetic analysis.

\section{Biochemical tests}

CEA, AFP, CA125 and CA19-9 measurements in serum: Roche Cobas e 601 autoanalyser was used in Roche brand commercial kits (Roche Diagnostics International Ltd., Rotkreuz, Switzerland). Results (CEA (ng / ml), AFP (ng / ml), CA125 (U/ ml) and CA19-9 (U/ ml)) were given.

\section{Genetic Analysis}

$30 \mathrm{mg}$ of tissue were used for analysis and isolated RNAs were kept at $-70^{\circ} \mathrm{C}$ and the process was completed. Real-time PCR was performed following the reaction steps with Light cycler Roche 480 device.

\section{Data analysis}

The analysis was performed using the 465-510 channel of the LightCycler 480 device. The change rates of the mRNA expression levels of the target genes were calculated by calculating the $2-\Delta \Delta \mathrm{Ct}$ method (PFAFFL, $2001)$ and results were given as an figure.

In genetic analysis $\beta$-actin (as house keeping gene); P53; Tnf- $\alpha$; ATF6; ATF4; CHOP; GRP78 and EDEM1 genes were used. CHOP, EDEM1, Tnf- $\alpha$; and P53 genes act as tumor suprossor genes. ATF6; ATF4; GRP78 act for carcinogenic effect.

\section{Primers:}
$\beta$-actin: NC 005111.4 Rattus norvegicus
F 5': GAGGGAAATCGTGCGTGACAT 3'
R 5': ACATCTGCTGGAAGGTGGACA 3'
P53: NC 005109.4 Rattus norvegicus
F 5': CGGAGGTCGTGAGACGCTG 3'
R 5': CACATGTACTTGTAGTGGATGGTGG 3'
Tnf- $\alpha$ : NC 005119.4 Rattus norvegicus
F 5': AGCCAGGCAGGTTCCGTCCCTC 3'
R 5': TTACTGTGCCCACCAGCCGAC 3'
ATF6: NM 007348
F 5': TCCTCGGTCAGTGGACTCTTA 3'
R 5': CTTGGGCTGAATTGAAGGTTTTG 3'
ATF4: NM 001675
F 5': TGGCTGGCTGTGGATGG 3'
R 5': TCCCGGAGAAGGCATCCT 3'
CHOP: NM 001195053.1
F 5:' AGAACCAGCAGAGGTCACAA 3'
R 5': TCTTCCTCCTCTTCCTGA 3'
GRP78: NM 005347.4
F 5': GGTGGATCACAAGGTCAAGAG 3'
R 5': CTACCACGCCCAGCTAATTT 3'
EDEM1: NM 014674.2
F 5': AGGTAGGGCTGAGTGATTACC 3'
R 5': GGCACTAGAATAGGAGCTGGA 3'

\section{Pathological Analysis}

The lung and intestinal tissues were passed through a series of alcohol (Leica TP 1020) series and xylene, and blocked in the paraffin. 6-8 microns thick sections were obtained by Rotary microtome (Leica RM 2155). All sections were stained with Hematoxylin Eosin (HE). Zeiss ICC 5 camera was evaluated by ZEN imaging software in light microscope (Zeiss Axiolab.A1) and microscopic images were taken.

\section{Statistical analysis}

In the analysis, independent samples $t$-test ( $t$ test) was applied for the variables containing two groups. ANOVA analysis was applied to compare the difference between the groups. Results are expressed as mean \pm standard deviation. Kolmogorov Smirnov test was used to test whether the continuous variables were normally distributed and $p<0.05$ was determined as significance level. The data obtained from the study were analyzed with SPSS (Statistical Package for Social Sciences) 18.0 program. 


\section{Result}

1-Biochemical Results:

Table 1. Comparison of DMH and control groups

\begin{tabular}{|c|c|c|c|c|c|}
\hline & $\mathbf{N}$ & mean & 1.quartile & 3.quartile & $\mathbf{P}$ \\
\hline CEA & 17 & 0,2 & 0,2 & 0,2 & 1 \\
\hline CA19-9 & 17 & 8,609 & 0,915 & 5,01 & $0,013 *$ \\
\hline CA125 & 17 & 0,602 & 0,6 & 0,6 & 0,643 \\
\hline AFP & 17 & 0,53 & 0,5 & 0,602 & $0,002 *$ \\
\hline
\end{tabular}

$\mathrm{p}>0,05$

According to Table 1 , a statistically significant difference was found between CA19-9 and AFP values of $\mathrm{DMH}$ and control groups $(p<0.05)$. In DMH application the CA19-9 value was very high, indicating a cancerous effect of DMH, and after SC and SLO application, these values decreased significantly, indicating SC and SLO effected and the carcerous effect was reduced in a curative direction and SC yielded better results than SLO in treatment success. In terms of AFP, using as an tumor marker, there was also successfully decrease in SC applied group.

Table 2. $\mathrm{DMH} ; \mathrm{DMH}+\mathrm{SC}$ and $\mathrm{DMH}+\mathrm{SLO}$ comparison

\begin{tabular}{|l|l|l|l|l|l|}
\hline & $\mathbf{N}$ & mean & 1.quartile & 3.quartile & P \\
\hline CA125 & 14 & 0,602 & 0,6 & 0,6 & 0,513 \\
\hline CEA & 14 & 2 & 0,2 & 0,2 & 1 \\
\hline CA19-9 & 14 & 8,609 & 0,5 & 5,01 & $0,003 *$ \\
\hline AFP & 14 & 0,530 & 0,915 & 0,602 & 0,745 \\
\hline
\end{tabular}

$p>0,05$

Table 2 shows, there was a statistically significant difference only in terms of CA19-9 values between DMH, $\mathrm{DMH}+\mathrm{SC}$ and DMH + SLO improvements $(p<0.05)$. In terms of CA19-9 tumor marker, the rats with DMH received more elevation than the other markers, and the
CA19-9 values decreased in DMH + SC and DMH + SLO groups. This decrease was found to be higher in SC than in SLO, indicating SC was more successful than SLO as treatment success.

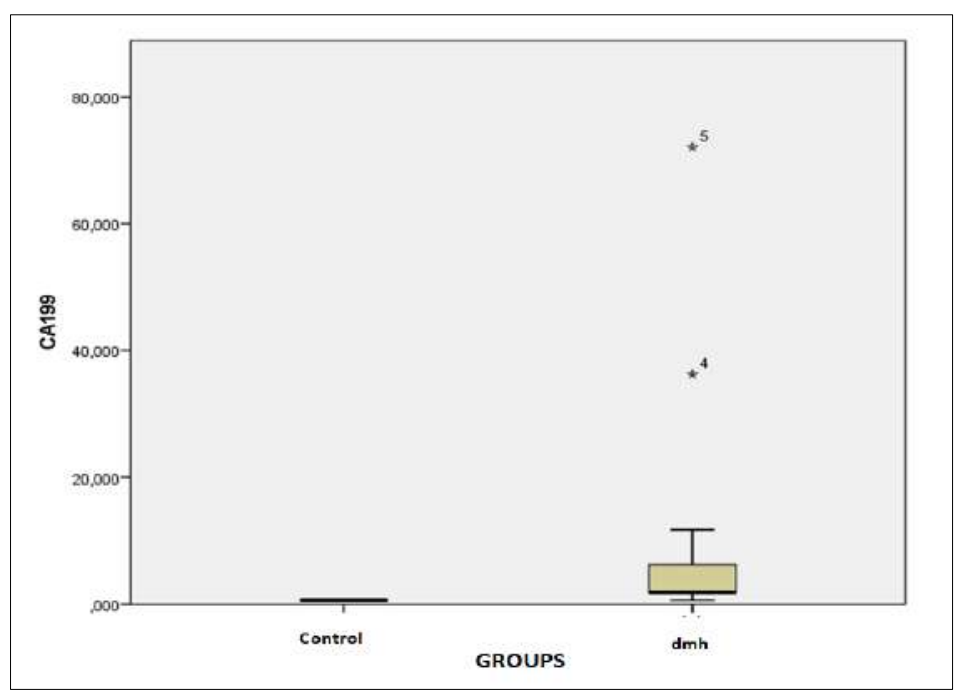

Figure 1. CA19-9 values of the control and DMH applied group. 
In the Figure 1, we found that CA19-9 values increased in DMH applied group, compared to control. According to this; It is seen that the increase in $\mathrm{DMH}$ administration compared to the control of CA19-9, which is used as a tumor marker, indicating a tumor formation as a sign.

\section{2-Genetic Analysis Result:}

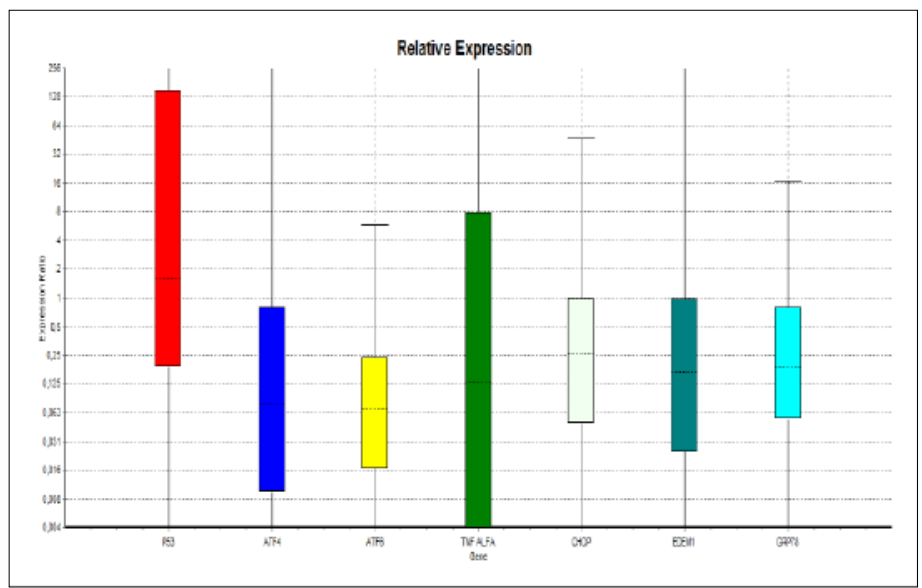

Figure 2. DMH- Genetic Analysis Chart
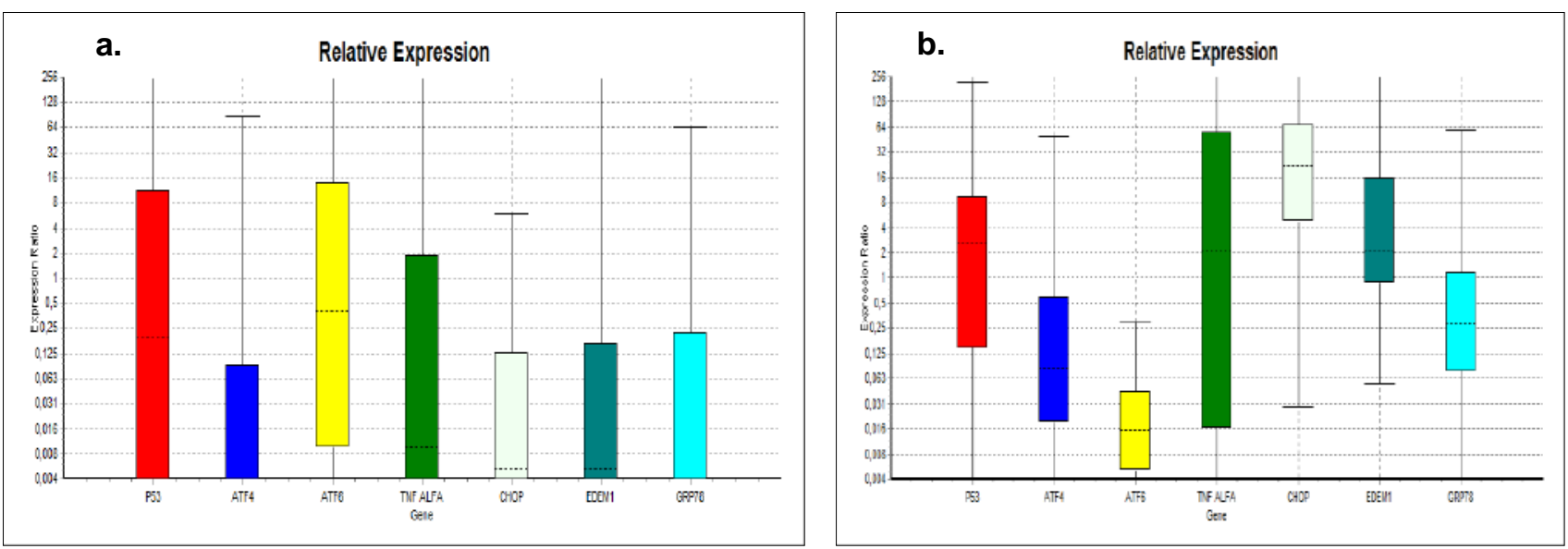

Figure 3. $\mathrm{DMH}+\mathrm{SLO}$ (a) and $\mathrm{DMH}+\mathrm{SC}$ Genetic Analysis Chart (b)

Figure 2 shows that; the use of DMH decreases the activity of CHOP and EDEM1 genes suggesting, DMH has a carcinogenic effect on tissues.

In the Figure 3, an increase in CHOP activity was observed in SC uptake with DMH. CHOP showed tumor suppressor effect with increased gene activity and SC began to show its therapeutic effect in tissues. Observation of a decrease in gene activity of ATF4 and ATF6 supports the curative effect of SC in tissues. In the DMH + SLO figure, the activity of the ATF4 and GRP78 genes decreased indicating and supporting that SLO has a therapeutic effect.

When we compared the therapeutic levels; in terms of increasing activity of CHOP and EDEM1 gene in $\mathrm{DMH}$ group and contrast to this decreasing activity on ATF4 and ATF6, SC was found to be more successful than SLO.

There was no significant difference in the activity of other genes. 


\section{3- Pathological Result:}

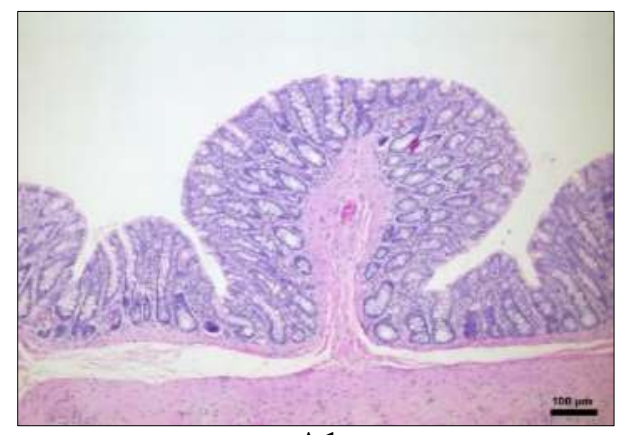

A1

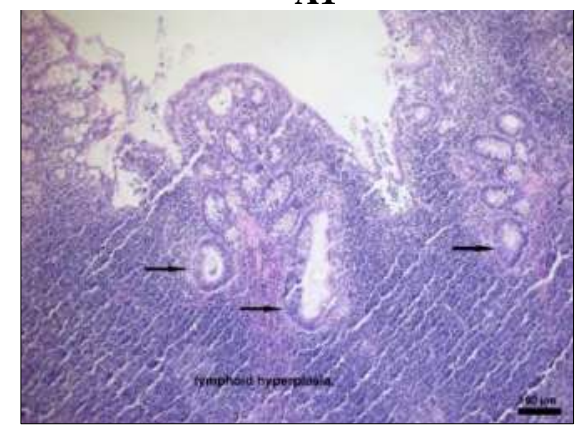

C4

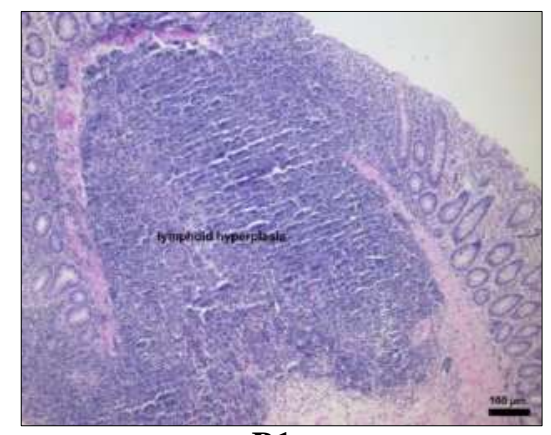

B1

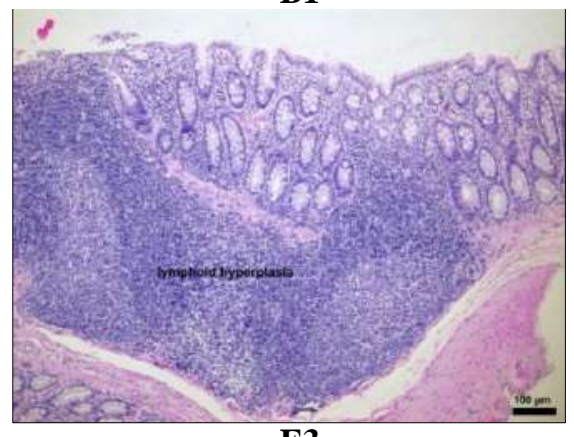

E3

Figure 4. Pathology Results of DMH applied Rats' for forming of Colon Cancer.

The sample in A1 belongs to the control group. No chemical substances were given during the working period in this group. The result belongs to a normal-looking intestinal tissue.

The sample in B1 is the intestinal tissue of a rat belonging to the group whose colon cancer is tried to be established by giving only DMH. Severe lymphoid hyperplasias developed at the end of the study.

The sample tissue in $\mathrm{C} 4$ belongs to the group that was treated with SC after being given DMH. In this tissue, severe lymphoid hyperplasias were reduced to lymphoid hyperplasia. It is seen that there are dysplasic glands in 3 different regions of lymphoid hyperplasia. The arrow marks indicate dysplastic glands.

The sample tissue in E3 belongs to the group tried to be treated with SLO after DMH is given. In this tissue, severe lymphoid hyperplasia is seen to regress to lymphoid hyperplasia.

Table 3. Scoring Table for Colon Cancer Formation with DMH

\begin{tabular}{|l|c|c|}
\hline \multicolumn{1}{|c|}{} & Displasy & Lenfoid Hyperplasy \\
\hline Control & 0 & 0 \\
\hline DMH & 0 & 3 \\
\hline DMH +SLO & 0 & 2 \\
\hline DMH + SC & 2 & 2 \\
\hline
\end{tabular}

SCORING: 0 . None; 1. Mild Severe; 2. Moderate; 3. Severe; 4. Very Severe

\section{Discussion}

It is seen from several studies that different doses of DMH are applied at different times in order to create experimental cancer.

In this study, male Wistar rats were divided into 6 groups. DMH was not given to the negative control group and DMH (20 mg/ kg v.a.) was injected into the control group. The remaining 4 groups were $\mathrm{DMH}+\mathrm{F}$. Assa-foetida extract given as chemopreventive and chemotherapeutic (6.25 and $12.5 \mathrm{mg} / \mathrm{Kg} \mathrm{v}$.a.), for the measurement of extract effects, the hepatic oxidative stress/antioxidant parameters, MDA, GSH, and iron reduction capacity in plasma (FRAP) detoxification, GST and Cytochrome P450 were determined. According to the results, F. assa-foetida extracts significantly changed the 
elevated levels of CYP450, FRAP and $\beta$-catenin into reverse, and also adjusted GST (activity and protein) and GSH levels as well. Histological analysis of liver tissue in the extracted groups showed that the formation of abnormal crypt foci was decreased with consistent of above results. The results showed that the extracts have chemopreventive and chemotherapeutic effects in DMHinduced colon cancer, and their beneficial effects on DMH metabolism processes in the large intestine (FATEMEH et al, 2015). In this study, colon cancer was induced by DMH application and it was observed that dysplasias developed as early stage cancer indication in colon tissue, as in our experimental model.

In one study, it was found that the tumor was completely prevented when the cartilage from a hen rabbit was placed next to the tumor in experimental animals (RIBATTI and FOLKMAN, 2008). This study is compatible with findings of our study that the anti-angiogenesis feature of the cartilage.

In another study, the effect of SC on the immune system was investigated. This is done by isolating shark protein fragments. These fragments have been shown to reduce the cytotoxic effect of lethal cells on mice. In addition, these parts injected intraperitoneally to the tumorbearing mice to improve the filtration of the $\mathrm{T}$ cells to the tumor and tumor area was observed to shrink. In order to examine the effect of cartilage on tumor growth, 15 rats were divided into two groups and a subcutaneous breast tumor was inoculated. Group 1 for 5 days with $0.1 \mathrm{ml}$ (100 mg / kg / day protein), shark cartilage, which is given subcutaneously, was applied while the control group 2 treated with only salts. In Group 1 with cartilage injected the tumor growth was seen significantly slowed down while in the control group, no change in the tumor was noted. It is believed that the antiangiogenic effect of the shark cartilage was done via matrix metalloproteinases (MMPs) inhibitory effect and by inhibiting the binding of angioid endothelial growth factor (VEGF) to endothelial cells. According to these results, the effective components in cartilage and its contents are seen as candidate materials for the treatment of cancer (HASSAN et al, 2005). The results of this study, in which the effect of SC on the immune system was supported, showed similar results with our study.

Another study was carried out to determine the mechanism of action of a pyroglutamate-modified peptide (pE-K092D) on in vitro growth inhibition of MDA-Pca-2b prostate cancer cells. This peptide was obtained from a peptide formerly isolated from the testis of the lesser spotted dogfish and identified as QLTPEALADEEEMNALAAR (K092D). The effect of this peptide on cell death mechanisms and proliferation was searched with flow cytometry. Results showed the 2624 inhibition of cell proliferation and at the end nonapoptotic cell death mechanisms, indicating all these formations seem to support MDA-Pca-2b growth inhibition via cytostatic end. This study findings, supports shark derived peptide inhibits cancer cells growth promoting related our findings (BOSSEBOEUF et al, 2019).

The angiogenic effect of SLO on tumor cell vaccinated mice was investigated in a study. It was reported that the component called Ecomer in SLO, suppressed the formation of new vessels and increased blood gronulocyte count in a sarcoma L-1 type tumor-bearing mouse (SKOPINSKA et al, 1999). In this study, the Ecomer component can be understood to increase the number of blood gronulocytes by enhancing the immune system in parallel with SLO finding in our study.

\section{Conclusion}

The negative effects of DMH on biochemical, genetic, and pathological were observed in rat column; The treatment of SLO and SC against to colon cancer is thought to be associated with damage and regression of tumor cells. When we look at the numerical results, it can be said that SC is more successful and effective in correcting the cancerogenic effect of DMH. In this respect, it can be said that our experimental model provides the desired aim and success. On the other hand, it is thought that further studies with broader participation are needed to elucidate the biochemical, genetic and pathological level of colon cancer treatment options and / or preventable pathways before emergence.

\section{Conflict of Interest}

The authors have no conflict of interest to declare.

\section{References}

1. AKGÜL E, DOSAY-AKBULUT M. Use of Complementary or Alternative Medicine In Patients With Cancer In Turkey, J of US-China Med Sci. 2014; 11(3): 159-167.

2. AKTARUL IS, VIJAY M, SIVARANJANI A, NISHA ST et al. Asiatic acid attenuates pre-neoplastic lesions, oxidative stress, biotransforming enzymes and histopathological alterations in 1,2-dimethylhydrazineinduced experimental rat colon carcinogenesis, Toxicol Mech methods. 2017; 27(2): 136-150.

3. BAYDAR H. Tibbi, aromatik ve keyf bitkileri. Yayın no:51. Süleyman Demirel Üniversitesi, Ziraat Fakültesi. Isparta. 2005.

4. BOSSEBOEUF A, BARON A, DUVAL E et al. A Potential Antineoplastic Peptide of Human Prostate 
Cancer Cells Derived from the Lesser Spotted Dogfish (Scyliorhinus canicula L.). Mar Drugs. 2019; 17(10). pii: E585. doi: 10.3390/md17100585.

5. FATEMEH T, DADKHAH A, FATEMI F, DINI S et al. Prevention and therapy of 1,2-dimethyl hydrazine induced colon carcinogenesis by Ferula assafoetida hydroalcoholic extract / 1,2-dimetilhidrazin ile indüklenmiş kalın bağırsak kanserlerinin Ferula assa-foetida ekstraktı kullanılarak önlenmesi ve tedavisi. Turk $J$ Biochem. 2015; 40(5): 390-400.

6. GLOBOCAN. Estimated Cancer Incidence, Mortality and Prevalence Worldwide in 2012. v1.0 IARC Cancer Base No. 11. Edited by Ferlay J, Soerjomataram I, Ervik M, Dikshit R, Eser S, Mathers C, Rebelo M, Parkin DM, Forman D, Bray F. Available at: http://globocan.iarc.fr/Pages/fact sheets_cancer.aspx/ 2012.

7. HASSAN ZM, FEYZI R, SHEIKHIAN A, BARGAHI $A$ et al. Low molecular weight fraction of shark cartilage can modulate immune responses and abolish angiogenesis. Int Immunopharmacol. 2005; 5(6): 961-70.

8. IAGHER F, DE BRITO BSR, SOUZA WM, NUNES JR et al. Antitumor and anti-cachectic effects of shark liver oil and fish oil: comparison between independent or associative chronic supplementation in Walker 256 tumor-bearing rats. Lipids Health Dis. 2013; 12.146.

9. JEYAMOGAN S, KHAN NA, SİDİQUI R1. Animals living in polluted environments are a potential source of anti-tumor molecule(s). Cancer Chemother Pharmacol. 2017; 80(5):919-924. doi: 10.1007/ s00280-017-3410-x
10. KURAGUCHI M, COOK H, WILLIAMS ED, THOMAS GA. Differences in susceptibility to colonic stem cell somatic mutation in three strains of mice. J Pathol. 2001; 193: 517-521.

11. LEWKOWICZ P, TCHORZEWSKI H. Anti-tumor activity of 1-O-alkylglycerols - the main component of shark liver oil. Pol Merkur Lekarski. 2012; 33(198): 353-357.

12. PATRA D, SANDELL LJ. Antiangiogenic and anticancer molecules in cartilage. Expert Rev Mol Med. 2012; 14: e10. doi: 10.1017/erm. 3.

13. PFAFFL MW. A new mathematical model for relative quantification in real-time RT-PCR. Nucleic Acids Res. 2001; 29 (9): e45.

14. RIBATTI D, FOLKMAN J. A pioneer in the study of angiogenesis. Angiogenesis. 2008; 11(1): 3-10.

15. SIDDIQUE AI, MANI V, ARIVALAGAN S, THOMAS NS et al. Asiatic acid attenuates preneoplastic lesions, oxidative stress, biotransforming enzymes and histopathological alterations in 1,2-dimethylhydrazine-induced experimental rat colon carcinogenesis. Toxicol mech methods. 2017; 27(2): 136-150.

16. SKOPINSKA RE, KROTKIEWSKI M, SOMMER E, ROGALA E et al. Inhibitory effect of shark liver oil on cutaneous angiogenesis induced in Balb/c mice by syngeneic sarcoma L-1, human urinary bladder and human kidney tumour cells. Oncol Rep. 1999; 6(6):1341-4.

17. VALCARCEL J, NOVOA-CARBALLAL R, PÉREZMARTÍN RI, REISS RL et al. Glycosaminoglycans from marine sources as therapeutic agents. Biotechnol $A d v .2017 ; 35(6): 711-725$. 